\title{
Effects of holothuria extract on pain behaviour and Fos like immunoreactivity (FLI) in formalin pain
}

\author{
Che Badariah $\mathrm{AA}^{\mathrm{a}}$, Asma HA ${ }^{\mathrm{b}}$, Mohd Nizam $\mathrm{H}^{\mathrm{c}}$, Siti FA
}

a Department of Physiology, School of Medical Sciences, USM Health Campus, 16150 Kubang Kerian, Kelantan, Malaysia

${ }^{b}$ FMRIB Centre, John Radcliffe Hospital, Headington, Oxford OX4 1AU

c Department of Physiology, School of Medical Sciences, USM Health Campus, 16150 Kubang Kerian, Kelantan, Malaysia

d School of Health Sciences, USM Health Campus, 16150 Kubang Kerian, Kelantan, Malaysia

\begin{abstract}
Introduction: The aim of this study was to determine the effects of gamat extract on pain behaviour and Fos like immunoreactivity (FLI) expression in the ventral posterolateral thalamus using the acute pain model. Materials \& Methods: Fourteen Sprague-Dawley male rats (220-300 gram) were given intraplantar injection of $0.05 \mathrm{ml}$ formalin $(1 \%)$ followed by intraperitoneal administration of either $4 \mathrm{mg} / \mathrm{kg}$ gamat extracts (Holothuria spp.) or saline (control). Behavioural changes were observed and rats were sacrificed 2 hours post-formalin injection. Immunohistochemistry testing was done on the brain sections. FLI was examined using a light microscope attached to an image analyser. The behaviour and FLI data were analysed using repeated measure analysis of variance and independent t-test respectively. Significance level was taken as $p<0.05$. Results: The control group has significantly higher pain scores compared to holothuria group $(F(1)=13.635, p=0.003)$. There was significant reduction in the pain behaviour score in the holothuria group when compared to the control group in phase $1(\mathrm{t}(14)=2.9, \mathrm{p}=0.012)$ and most of the time from 15 to 60 minutes post-formalin injection $(t(12)=3.535, p=0.004)$. There was a significant reduction $(P<0.05)$ in the number of FLI on the contralateral aspect of the ventral posterolateral thalamic nucleus in the group that received $4 \mathrm{mg} / \mathrm{kg}$ of holothuria extract $(63 \pm 3.18)$ compared to control group $(84 \pm 6.36)$. Conclusion: This study showed that administration of holothuria extract significantly suppressed the pain behaviour and reduced the number of FLI in formalin injected rats compared to control.
\end{abstract}

KEYWORDS: Pain, behaviour, holothuria

\section{INTRODUCTION}

$\mathrm{C}$-fos and its protein products are expressed in the neurons in response to noxious stimulation and they induce conversion of information encoded in the c-fos gene to messenger RNA rapidly within minutes after a particular stimulus and transiently. ${ }^{1,2}$ Further, c-fos is widely used as a tool in pain research and is a marker for neuroplasticity. ${ }^{3,4}$ Neuroplasticity is initiated by afferent input generated by intense noxious stimuli that trigger an increased excitability of nociceptive neurons in the central nervous system. ${ }^{5}$ Neuroplasticity is expressed clinically as pathological pain e.g. hyperalgesia and allodynia. It is important to prevent neuroplasticity from occurring as 'pathological pain' is more difficult to treat. ${ }^{6,7}$

\section{Corresponding author;}

Che Badariah Ab Aziz

Department of Physiology,

School of Medical Sciences,

USM Health Campus,

16150 Kubang Kerian Kelantan, Malaysia

Email:badariah@kb.usm.my
There are evidences for the important role of the ventral posterolateral thalamic nucleus in pathological pain responses. ${ }^{8,9,10}$ Studies have shown that the ventrobasal thalamic neurons had lower thresholds to pain and their peripherally-evoked responses were enhanced following hindpaw inflammation and nerve injury. $9,10,11$ Furthermore, the $\mathrm{N}$-methyl-D-aspartate (NMDA) receptors in the thalamus contributed to hyperalgesia in the rat model of inflammatory pain. ${ }^{12}$ Studies have shown that c-fos is expressed in the central nervous system in this acute pain model. ${ }^{13,14}$ Inhibition of c-fos expression in the central nervous system has been shown by modern medication e.g. morphine and ketamine. ${ }^{15,16}$

A traditional medication, gamat (Holothuria spp) was shown to promote tissue healing and it was widely used for wound healing in the postpartum period. ${ }^{17,18,19,20}$ Another report has demonstrated the antinociceptive property of gamat. ${ }^{21}$ Gamat administration in mice has inhibited the abdominal contraction induced by acetic acid. ${ }^{21}$ However, up to date, very little is known regarding the effects of gamat on c-fos expression in the central nervous system. The main aim of the present study was to determine the effects of gamat extract on pain behaviour and c-fos expression in the thalamus using the formalin pain model. Results from this investigation could throw 
some light as to the possible interaction of the gamat extract with function of the nervous system involved in pain modulation.

\section{MATERIALS AND METHODS}

\section{Animals}

Fourteen adult male Sprague-Dawley rats weighing between 220-300g were involved in the study. The rats were housed in individual cages and allowed adaptation for at least three days in the Physiology Department laboratory. They were maintained in a 12-hour light dark cycle and allowed free access to food and water. Investigations were conducted between 0800 and 1600 in the Physiology Department laboratory. Animals were obtained from Laboratory Animal Research Unit, Universiti Sains Malaysia (LARUSM). The present study was approved by the Animal Ethics Committee of Universiti Sains Malaysia.

\section{Preparation of holothuria extracts}

A dissection was made on the gamat and the internal organs were removed. An air oven (Binder BD 115) was used to dry the gamat tissues at $58^{\circ} \mathrm{C}$ for two weeks. Following this, the tissues were then blended to produce powder material. Petroleum ether was mixed with the powder material before the solution was then poured into a funnel. The material was collected in a beaker and was left to be separated into organic component (upper portion) and non-organic component (lower portion). The organic component was left to dry for 12 hours at $-48^{\circ} \mathrm{C}$ and 200atm us- ing freeze dry process (Ilshin Lab. Co. Ltd). ${ }^{22}$ These processes produced powder extract which was stored in a refrigerator until used.

\section{Drugs Used and Experimental Groups}

The rats were divided into two groups (gamat and saline) with 7 rats in each group. The experimental group (gamat) was given $4 \mathrm{mg} / \mathrm{kg}$ holothuria extracts while control rats were given saline. Holothuria extracts and saline were given at a volume of $1 \mathrm{ml} / \mathrm{kg}$ and administered intraperitoneally.

\section{Behaviour testing}

Both groups of rats were given intraplantar injection of $0.05 \mathrm{ml}$ formalin $(1 \%)$ followed immediately by either intraperitoneal holothuria extract or saline according to their respective groups. They were then observed for behavioural changes for an hour before being sacrificed and the brain removed for immunohistochemistry testing as described below. ${ }^{23}$ The behavioural data were analysed by two observers blinded to the treatment of each rat and behaviour pain score was tabulated at each minute and averaged at 5-minute intervals. ${ }^{23}$ The quantification was based on the total time spent in 4 behavioural categories. ${ }^{23,25}$

\section{Sacrifice of Animals and Perfusion-fixation of thala-} mus

All rats were sacrificed with an overdose of sodium pentobarbitone intraperitoneally 120 minutes after formalin injection. ${ }^{26}$ Thoracotomy was performed and

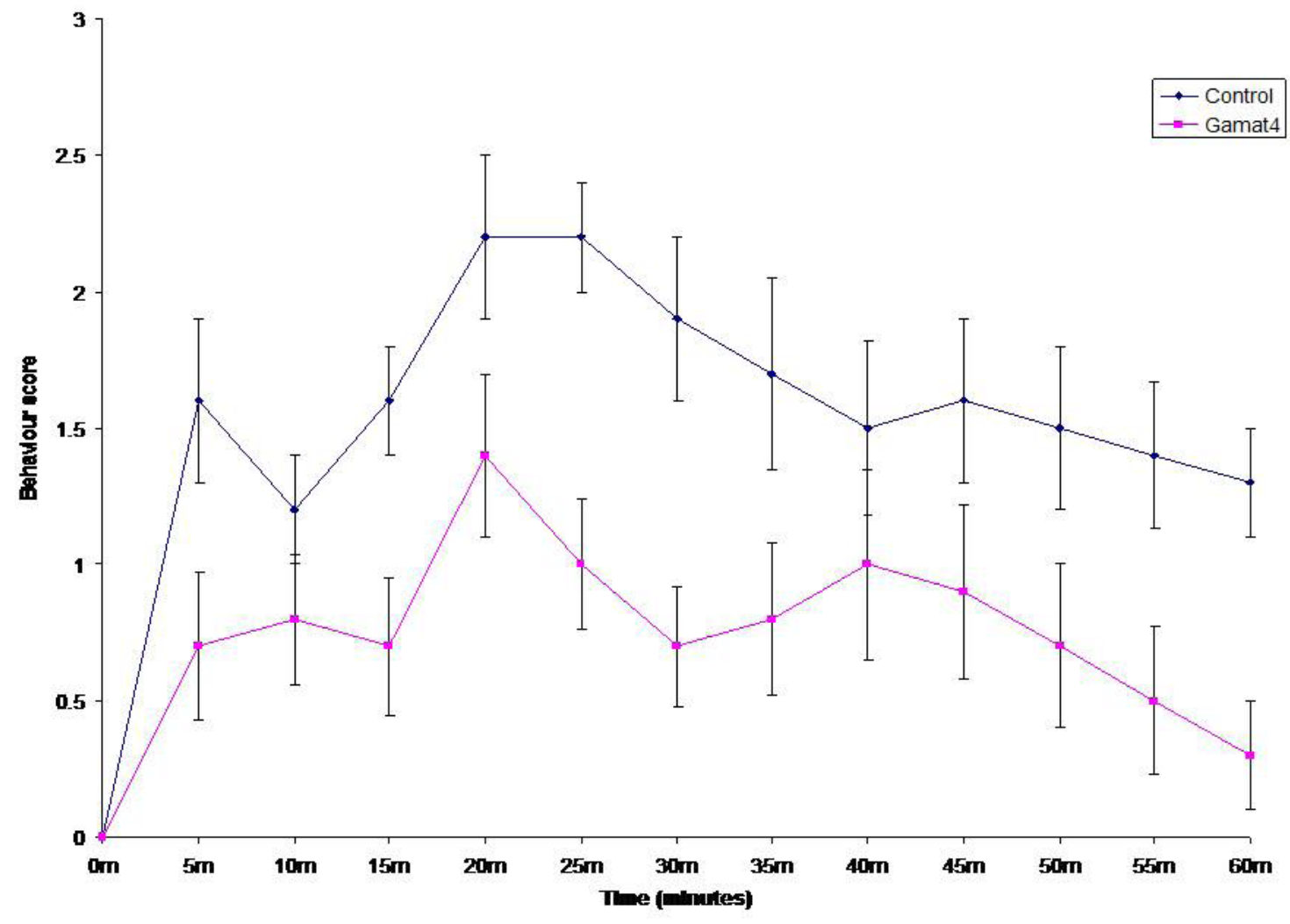

Figure 1: Behaviour score in the group receiving saline (control) and $4 \mathrm{mg} / \mathrm{kg}$ holothuria extracts (gamat 4) ( $n=7$ for both groups). Values are means \pm S.E.M ( $\left.{ }^{*} \mathrm{p}<0.05 ;{ }^{* *} \mathrm{p}<0.01\right)$ comparison between holothuria $4 \mathrm{mg} / \mathrm{kg}$ and control groups) 
the heart was exposed immediately following the lost of their pinch reflex. An $18 \mathrm{G}$ branula was inserted into the apex of the left ventricle and the right atrium was snipped with a pair of scissors. ${ }^{23}$ Perfusion was performed by gravity method using first phosphate-buffered saline (PBS) until the fluid ran clear, followed by $500 \mathrm{ml}$ of cold $4 \%$ paraformaldehyde in phosphate buffer $(\mathrm{PB}) 0.1 \mathrm{~mol} /$ litre $(\mathrm{pH}=7.4) .23,27,28$ The brains were then removed from the cranial cavity.

\section{Dissection of Brain and Cryostat Sectioning}

The brains were post-fixed in fresh perfusion solution (4\% PFA in PB $0.1 \mathrm{M}$ ) at $4^{\circ} \mathrm{C}$ for 4 hours, and cryoprotected overnight in $20 \%$ sucrose in phosphate buffer $0.1 \mathrm{M}$ at $4^{\circ} \mathrm{C} .29$ The brains were next embedded in tissue freezing medium (Jung) and sliced into 20- $\mu \mathrm{m}$ sections using a cryostat. 27 Sections were transferred using a paintbrush to a 24-well multiwell plate containing $500 \mu$ of PBS in each well.

\section{Immunohistochemistry}

A three-step peroxidase avidin-botin complex (ABC) method (purified primary antibody, biotinylated secondary antibody, and $A B C$ with $D A B$ ) was used to stain the brain sections for localising fos protein. ${ }^{30}$ The immunohistochemistry test was performed as described previously by Asma Hayati et al. ${ }^{23}$ Following the test, all sections were mounted on gelatin-subbed slides and air-dried overnight. Slides were then dehydrated with absolute ethanol for 15 minutes, mounted with Styrolyte Mounting Medium and protected with a cover slip. 23,31

\section{Counting of fos like immunoreactivity (FLI) labelled neurons}

Sections were examined using light microscopy attached to an image analyzer (Leica QWin) and ventral posterolateral thalamic nucleus was determined using the rat's brain atlas. ${ }^{32}$ Immunohistochemically detected nuclear-associated reaction product was referred to as $\mathrm{FLI} .{ }^{33} \mathrm{FLI}$ labelled neurons were counted by two blinded investigators and the counts were then averaged for each rat. Counts that were questionable in either quantity or quality were excluded. Images of the brain sections were captured at $\times 25$ to determine the area and at $\times 50$ to localize FLI labelled neurons.

\section{Statistical Analysis}

Pain behaviour scores by formalin test were analyzed using one-way repeated measures ANOVA with one within subjects factor (time: 13 levels) and two between subjects' factors (drug: 2 levels, holothuria extract and saline). Independent t-test was used to analyze the effects of Phase 1 formalin test (mean score at 5 minutes) and Phase 2 (mean of scores from 10 to 60 minutes) between saline and holothuria extract and significance level was accepted at $p<0.05$.

\section{RESULTS}

Effects of holothuria extract on pain behaviour.

In the control group, there was an increase in the pain behaviour score in the first five minutes (phase 1) followed by 5 to 10 minutes of reduced nociceptive behaviour (figure 1). Following this, increased pain behaviour was noted from 15 minutes to sixty minutes post formalin injection (phase 2). The control group has significantly higher pain scores compared to holothuria group $(F(1)=13.635, p=0.003)$. There was significant reduction in the pain behaviour score in the holothuria group when compared to the control group in phase $1(t(14)=2.9, p=0.012)$ and most of the time from 15 to 60 minutes post-formalin injection $(t(12)$ $=3.535, p=0.004$ ).

Effects of holothuria extract on FLI expression in the ventral posterolateral thalamic nucleus.

There was significant reduction $(p<0.05)$ in the number of FLI on the contralateral aspect of the ventral posterolateral thalamic nucleus (figure 2 ) in the group that received $4 \mathrm{mg} / \mathrm{kg}$ of holothuria extract $(63 \pm 3.18)$ compared to control group $(84 \pm 6.36)$. However, the number of FLI on the ipsilateral side was not significantly different in both of the groups (control: 26.4 \pm 2.96 ; holothuria: $21.4 \pm 1.50$ ) .

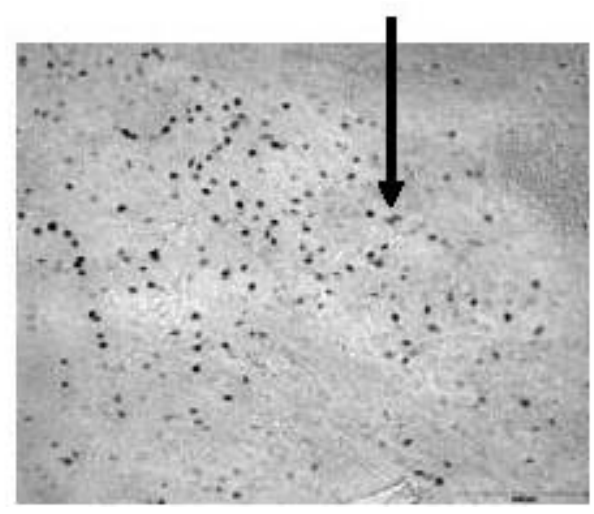

B

Figure 2: Photomicrographs showing FLI in contralateral side (left side) of ventral posterolateral thalamic nucleus in the (A) holothuria and (B) saline groups (50× magnification). Arrows indicate the dark staining FLI. 


\section{DISCUSSION}

In the present study, the effects of intraperitoneal administration of holothuria extracts on pain behaviour in an acute pain model were investigated. The group receiving $4 \mathrm{mg} / \mathrm{kg}$ of holothuria extracts demonstrated a significant reduction in pain behaviour compared to control in phase 1 and most of the time in phase 2 $(p<0.01)$. The analgesic property of gamat is in agreement with a report by Ridzwan et al. which demonstrated the ability of gamat extract to inhibit the abdominal contraction in acetic acid induced writhing test. ${ }^{21}$ In the present study, the formalin pain model was used. The formalin pain model was chosen as the pain mechanisms in this model are well-known; phase 1 is contributed by peripheral mechanism while phase 2 is mainly due to central nervous system hyperexcitability. ${ }^{34}$

Intraperitoneal administration of holothuria extracts ( $4 \mathrm{mg} / \mathrm{kg}$ ) has significantly inhibited the pain behaviour in both phases. Phase 1 involves chemical stimulation of nociceptors and activation of $C$ fibers in the periphery while hyperexcitability of central nervous system is involved in phase 2.23,25,34,35 The nociceptive behavior in phase 1 was partly contributed by the formation of prostaglandin that generated the signs and symptoms of inflammation. ${ }^{36}$ The activation of NMDA receptors that leads to hyperexcitable dorsal horn neurons as well as local inflammatory changes during the second phase, are necessary for the full manifestation of the second phase. ${ }^{34}$

The inhibition of pain behaviour in phase 1 and phase 2 of the present study suggests that holothuria extract

\section{REFERENCES}

1. Harris JA. Using C-fos as a neural marker of pain. Brain Res Bull 1998; 45(1):1-8.

2. Asma Hayati A, Zalina I. C-Fos and Its Conse quences in Pain. Malaysian J Med Sci 2002; 9:3-8.

3. Dubner R, Ren K. Brainstem mechanisms of persistent pain following injury. J Orofac Pain 2004; 18: 299-305.

4. Kosai K, Tateyama S, Ikeda T, et al. MK-801 reduces non-noxious stimulus-evoked Foslike immunoreactivity in the spinal cord of rats with chronic constriction nerve injury. Brain Res 2001; 910:12-8.

5. Ji RR, Woolf CJ. Neuronal plasticity and sig nal transduction in nociceptive neurons: implications for the initiation and mainte nance of pathological pain. Neurobiol 2001; 8:1-10.

6. Woolf CJ. A new strategy for the treatment of inflammatory pain. Prevention or elimina tion of central sensitization. Drugs 1994; 47:1-9.

7. Woolf CJ, Chong MS. Preemptive analgesia-treating postoperative pain by preventing the establishment of central sensitization. Anesth Analg 1993; 77:362-79. has the ability to modulate the peripheral and central mechanisms and leads to reduction in the pain behaviour. The peripheral effects of holothuria extract could be attributed by several possible mechanisms including inhibition of release of prostaglandin, substance $P$ or bradykinin in the inflammed peripheral tissue. ${ }^{37}$ Following holothuria extract administration, marked difference was observed in the effects of formalin injection on the FLI expression. FLI expression was markedly reduced on the contralateral side of the formalin injection. The reduction of FLI in the contralateral ventral posterolateral thalamic nucleus correspond to the significant reduction in the pain behaviour in phase 2 exhibited in the behavioural study. These results indicate that holothuria extract has a central effect and it was able to inhibit FLI expression in the ventral posterolateral thalamic nucleus following formalin injection. The reduction of FLI in the contralateral thalamus correspond to the significant reduction in the pain behaviour in phase 2 exhibited in the behavioural study. The present study has demonstrated the analgesic property of holothuria extract and further investigations should be done to assist in the understanding of its actions at the peripheral or central nervous system.

\section{ACKNOWLEDGEMENT}

The research was funded by Universiti Sains Malaysia through short term grant 304/PPSP/6131465 and the holothuria extract was contributed by Prof Syed Mohsin Jamalullail.

8. Abdul Aziz CB, Chapman V, Mason R. Com parison of responses of ventral posterolateral and posterior complex thalamic neurons in naive rats and rats with hindpaw inflam mation: $\mu$-opioid receptor mediated inhibi tions. Neuropharmacol 2005; 48:607-16.

9. Guilbaud G, Kayser V, Benoist JM, et al. Modifications in the responsiveness of rat ventrobasal thalamic neurons at different stages of carrageenin-produced inflamma tion. Brain Res 1986; 385:86-98.

10. Guilbaud G, Neil A, Benoist JM, et al. Thresh olds and encoding of neuronal responses to mechanical stimuli in the ventro-basal thala mus during carrageenin-induced hyperal gesic inflammation in the rat. Exp Brain Res 1987; 68:311-8.

11. Guilbaud G, Benoist JM, Jazat F, et al. Neuronal responsiveness in the ventrobasal thalamic complex of rats with an experimen tal peripheral mononeuropathy. J Neurophys iol 1990; 64:1537-54.

12. Kolhekar RS, Murphy S, Gebhart GF. Thalamic NMDA receptors modulate inflammation-pro duced hyperalgesia in the rat. Pain 1997; 7 $1: 31-40$. 
13. Buritova J, Besson JM, Bernard JF. Involve ment of the spinoparabrachial pathway in inflammatory nociceptive processes: a c-Fos protein study in the awake rat. J Comp Neu rol 1998; 397:10-28.

14. Nackley AG, Makriyannis A, Hohmann AG. Selective activation of cannabinoid CB(2) receptors suppresses spinal fos protein ex pression and pain behavior in a rat model of inflammation. Neuroscience 2003; 119:74757.

15. Catheline G, Le Guen S, Besson JM. Effects of opioid receptor antagonists on the effects of i.v. morphine on carrageenin evoked c-Fos expression in the superficial dorsal horn of the rat spinal cord. Brain Res 1999; 824(1):105-11.

16. Zhang GH, Min SS, Lee KS, et al. Intraar ticular pretreatment with ketamine and memantine could prevent arthritic pain: relevance to the decrease of spinal c-fos expression in rats. Anesth Analg 2004; 99:152-8.

17. Fredalina BD, Ridzwan BH, Abidin AA, et al. Fatty acid compositions in local sea cucumber, Stichopus chloronotus, for wound healing. Gen Pharmacol 1999; 33:337-40.

18. Taiyeb-Ali TB, Zainuddin SL, Swaminathan D, Yaacob H. Efficacy of 'Gamadent' toothpaste on the healing of gingival tissues: a prelimi nary report. J Oral Sci 2003; 45:153-9.

19. Chan EH, Liew HC. The sea cucumber. Nature Malaysia 1986; 10:8-12.

20. Zainudin M, Chua YT, Syed Zahir I, et al. Air gamat (Sea Cucumber [Holothurian]) extracts does not have B-adrenoceptor agonist or phosphodiesterase inhibiting prop erties. J Perubatan UKM 1986; 1:41-8.

21. Ridzwan BH, Leong TC, Idid SZ. The antinoci ceptive effects of water extracts from sea cucumbers Holothuria Leucospilota Brandt, Bohadschia marmorata vitiensis Jaeger and coelomic fluid from Stichopus hermanii. Pak J Biol Sci 2003; 8:2068-72.

22. Zury A. Assessment of general toxicity and analgesic property of several sea cucumbers species. Universiti Sains Malaysia 2004 (un published report).

23. Asma Hayati A, Zalina I, Myo T, et al. Modula tion of formalin-induced Fos-like immunore activity in the spinal cord by swim stressinduced analgesia, morphine and ketamine. Ger Med Sci 2008; 6:Doc05.

24. Sun WZ, Shyu BC, Shieh JY. Nitrous oxide or halothane, or both, fail to suppress c-fos ex pression in rat spinal cord dorsal horn neurones after subcutaneous formalin. $\mathrm{Br} \mathrm{J}$ Anaesth 1996; 76:99-105.

25. Dubuisson D, Dennis SG. The formalin test: a quantitative study of the analgesic effects of morphine, meperidine, and brain stem stimulation in rats and cats. Pain 1977; 4:161-74.
26. Hao S, Takahata O, Mamiya K, et al. Sevoflu rane suppresses noxious stimulus-evoked expression of Fos-like immunoreactivity in the rat spinal cord via activation of endog enous opioid systems. Life Sci 2002; 71:57180.

27. Gilron I, Quirion R, Coderre TJ. Pre-versus postinjury effects of intravenous GABAergic anesthetics on formalin induced fos immuno reactivity in the rat spinal cord. Anesth Analg 1999; 89:414-420.

28. Gogas KR, Cho HJ, Botchkina GI, et al. Inhibi tion of noxious stimulus-evoked pain behav iors and neuronal fos-like immunoreactivity in the spinal cord of the rat by supraspinal morphine. Pain 1996; 65:9-15.

29. Ji RR, Rupp F. Phosphorylation of transcrip tion factor CREB in rat spinal cord after formalin-induced hyperalgesia: relationship to c-fos induction. J Neurosci 1997; 17:177685.

30. Huang W, Simpson RK. Ketamine suppresses c-fos expression in dorsal horn neurons after acute constrictive sciatic nerve injury in the rat. Neurosci Lett 1999; 269:165-168.

31. Jennings E, Fitzgerald M. C-fos can be in duced in the neonatal rat spinal cord by both noxious and innocuous peripheral stimula tion. Pain 1996; 68:301-6.

32. Paxinos G, Watson WC. The rat brain in ste reotaxic coordinates. New York: Academic Press, 5th Ed 2004.

33. Nakao S, Miyamoto E, Masuzawa M, et al. Ketamine-induced c-Fos expression in the mouse posterior cingulate and retrosplenial cortices is mediated not only via NMDA re ceptors but also via sigma receptors. Brain Res 2002; 926:191-6.

34. TjØlsen A, Berge OG, Hunskaar S, et al. The f ormalin test: an evaluation of the method. Pain 1992; 51:5-17.

35. Malmberg AB, Yaksh TL. Hyperalgesia medi ated by spinal glutamate or substance $P$ receptor blocked by spinal cyclooxygenase inhibition. Science 1992; 257:1276-9.

36. Vane JR. Inhibition of prostaglandin synthesis as a mechanism of action for aspirin-like drugs. Nat New Biol 1971; 231:232-5.

37. Shibata M, Ohkubo T, Takahashi H, et al. Modified formalin test: characteristic bipha sic pain response. Pain 1989; 38:347-52. 